2020, Volume 10, International Conference Globalization, Innovation and Development. Trends and Prospects (G.I.D.T.P.), pages: 295-307 |

https://doi.org/10.18662/lumproc/gidtp2018/33

\section{Criminological Aspects of Violence against Women}

\section{Lavinia-Mihaela VLADILA $^{1}$}

${ }^{1}$ Faculty of Law and Administrative Science, Valahia University of Targoviste, Targoviste, Romania, laviniavladila@yahoo.com
Abstract: Violence against women is one of the social and legal paradoxes of our times. Regardless of the social development and the cultural or religious edges, it is found, in all European states and in all social layers. The current study aims to discover the preponderances in the social environment in which we often see this obscure form of violence, descending from ancient times until nowadays. We aim to identify the preponderant age of the victims, but also of the aggressors, their occupation, the causes of the violence against women most often occurring between partners. Our study shall present some of the statistics, in fact poor, currently existing in Romania. Reducing violence against women by understanding its social mechanisms and by appropriate legal response is a way of social responsibility for each of us.

Keywords: violence against women; causes; effects; criminological aspects.

How to cite: Vladila, L.M. (2020). Criminological Aspects of Violence against Women. In I. Panagoreț \& G. Gorghiu (vol. ed.), Lumen Proceedings: Vol. 10. International Conference Globalization, Innovation and Development. Trends and Prospects (G.I.D.T.P.) (pp. 295-307). Iasi, Romania: LUMEN Publishing House. https://doi.org/10.18662/lumproc/gidtp2018/33 


\section{Introduction.}

Violence in general, and in particular, domestic violence with its various nuances is an increasingly widespread plague in society, requiring greater attention and control by the judicial bodies. Currently, the domestic violence represents not just a social issue, but also one of public health and a means of discrimination and conceptual inequity between the two sexes [1]. The careful study of this social manifestation cannot omit a criminological analysis. For this, we shall present first of all the different theories regarding the nature and causes of this phenomenon.

\section{Theoretical Background.}

For the study, I have used Romanian and Spanish literature, completed by some American study of the kind. For support the criminological analysis, I have presented some statistics from Romania. The importance of the article results in the facts that gather all together the most relevant theories about the gender based violence.

\section{Argument of the paper.}

The key idea of the paper is to reveal the phenomenon of the gender based violence in Romanian society and to discover his causes beyond any doubt. I also, intend to propose the juridical adequate measure to limit or to eradicate it.

\section{Arguments to support the thesis.}

The issue of gender based violence has entered under the attention of criminologists between 1980 and1990, by three different approaches [2]:

- the first, started in its analysis from the study of the quantitative and qualitative of this phenomenon, with the emergence of the first statistics in this area;

- the second, it emphasized on the victims of the domestic violence, by discovering that mostly, the women, but also children, elders and handicapped persons, namely the persons who are being vulnerable under a certain aspect; 
- finally, the last approach was of the different feminist trends, who was most an American point of view.

Each phase, of the three moments from those presented above, has his importance: the first provided some statistics, absolutely necessary to understand the dimension of the phenomenon, and to take the first legal steps to protect the victims; the second was necessary to discover all the victims of the domestic violence and to understand some part of its causes, and la last, but not the least, had revealed the different form of violence, and especially the fact the majority of the victims were women.

From this final step, our article presents the ultimate theories in the domain of violence against women.

A first dichotomy that was made in the analysis of the causality of gender based violence was proposed by Iolanda Beldianu [3], in the form of psychological and sociological approaches, each of them presenting several options. In a synthetic presentation, here are the main ideas supported by the psychological theories [4]:

a) For the physiological model, it is considered that violence performed by men, in their maturity can be explained also by the physiological issues they had during childhood, especially as attention disorders or cerebral traumas. Statistically it resulted that over half of the violent men showed a history of brain trauma, unlike the men who did not developed a violent behavior, where the percentage of such problems was almost a quarter. A study conducted by the WHO regarding violence prevention, emphasizes 4 levels of risk and of intervention, generating violence, and especially gender based violence. According to level 1, so-called the individual level, the risk for abusive-violent behaviors is due both to past experiences of abuse and rejection, as well as to certain diseases or mental disorders of the aggressor [5].

b) For the psychopathological model, the explanation of the development of a violent behavior resides in the weak personality of the aggressor, with a series of destabilizing experiences, pathological jealousy, frustrations determined by certain expectations of a surreal model about the role of the man in the family, as well as the inner lack of power and (self)control. AuricaSăndulescu and AlinaPopescu also expressed the view that violent behavior is determined by the absence of self-confidence, the inclination towards violence of the aggressor, the existence of degenerative jealousy and possessiveness, emotional immaturity, combined with a state of attitude instability, all of which are pigmented by the deeply erroneous belief that power and control can be obtained through violence and the existence of a negative attitude towards the woman [6]. For Livia-SimonaGafton and Maria-NicoletaTurlic, an important element of domestic violence is 
represented by the pathological jealousy which in this case it becomes the desire to possess and control over the partner [7]. For the above-mentioned authors, jealousy is generated by internal factors, such as low self- esteem, anxiety, poor affective maturation, hostility, elements completed by others of conjunctural or exterior nature, such as: the partner's behavior, gender, civil status or infidelity. Starting from the premise of gender based differences in the manifestation of jealousy, we can state that these are present also for domestic violence, in the meaning that in most cases it is generated by men, especially partners or relatives, with the purpose of control. Without any doubt that men can also be targets for violence, but in most cases, they are the target of aggression performed by other men. Violence against women reflects the unequal relations of power between men and women, serving for the perpetuation of these unequal relations [7].

This theory has created a model of the victim, for most cases a woman, who was considered of having a personality attractive for the aggressor. The theory, in this case, emphasized on the victim and not on the uncontrolled behavior of the aggressor, making her the main cause of the aggression, without really solving the issues of such a couple and without proposing viable solutions.

c) The model of social learning or the intergenerational passing of the violent behavioral model emphasis the idea of the learned behavior, taken over by imitation and transmitted from one generation to the next [6]. In Romania, it is believed that $75 \%$ of the children assisting to a violent parental relationship, become violent in their own couple relationships which is, let's face it, an alarming percentage. The model of learned behavior combined with child abuses, are considered as the roots of gender based violence also by other authors, such as Maria-Laura Lupșa, ZoiaGhesnoiu [8] or AuricaSăndulescu and AlinaPopescu [6]. Also, the study conducted by the WHO above mentioned, the fourth level of risk, and the last one, on the generation of gender based violence, is the structural level, according to which the violence between partners is determined by its cultural tolerance, by the promotion of rigid gender roles or by the promotion of masculine domination [5].

But such a doctrine of behavior is found in both feminine and masculine patterns. In other words, men learn that their power over their partner can be maintained, if necessary by violence, and women learn to accept such attitude, which is considered as traditional and thus "normal". In the same meaning is the opinion of French author Pierre Bourdieu, stating that in some states (after studying the life style of an Algerian tribe) violence against women is still considered as a right of men over them, as result of the culture and macistic traditions perpetuated throughout generations [9]. As opposed to this situation, is the fact that there still are tribal societies, 
such as those from Java, Thai or Australia, where men rarely aggress women because, if this would happen, they would be excommunicated, which is equivalent with a social death, being a harsh punishment, but well deserved, which succeeded into stopping the phenomenon over time [10].

d) Finally, the last model of this type of psychological theories, belongs to the exosystemic interactive model. The model starts from a detailed analysis of the circumstances in which the violent behavior emerges, most often revealed as collateral "actors" of the process, chronicling social situations of inferiority (unemployment, poverty, inadequate living conditions) which are not properly managed by the aggressor, so that his final solution for these problems is rage, turned into violence. The same conclusion results from the above-mentioned study concluded by the WHO, according to which the third level of risk in generating gender based violence is the institutional level, which refers to the existence of a low socio-economic statute (material and financial difficulties) or to the presence of unemployment or to the existence of discontent at the workplace [5,6 and 8]. By applying these conclusions to the current situation in Romania, CătălinaNicu considers that the economic recession, social and moral crisis in which the Romanian society has been going through for the past two decades, inflation, the increasingly striking economic inequalities, combined with feelings of frustration, insecurity, and the existence of some subculture environments and improper life, are the most common ingredients for domestic violence [1].

\section{Arguments to argue the thesis.}

\section{From a sociological point of view, the approach of violence has been made using different typeof visions:}

a) The cost-benefit theory or the theory of exchangestates, more likely, lack of the Romanian legal system for sanctioning such behavior, but also the low level of dignity of such characters and their lack of education and superior conscience. For the aggressors the "benefit" of maintaining a relation of power through violence seems higher than the minimal "costs", determined by the frequent situations of social and legal non-punishment of such behavior.

b) The theory of resources - in such case the emphasis is on the way in which the aggressor sees his relationship. His sentimental universe is limited to the master-slave relation, in which after the exhaustion of the other solutions or resources (quite limited too - such as poor communication, low incomes etc.) for conflict resolution, sooner or later the violence is reached. 
By developing the theme of jealousy as one of the frequent reasons for domestic violence, either with support, or as pathological manifestation, Livia-SimonaGafton and Maria-NicoletaTurliuc have discovered that the persons with middle-class education have a more prominent jealousy, precisely because of the medieval mentality of the "master-slave" type, considering their life partner as a commodity, a good of their own, with whom they think they can do anything, they can claim anything, and sometimes they can force their will through violence. Unlike them, persons with higher education, though they can manifest a minimum level of jealousy, they can control their feelings, can separate themselves from this negative feeling probably because of the need to preserve an impeccable social statute [7].

c) The feminist or patriarchal theory in which, as previously showed, the relation man-woman is dominated by the patriarchal concept, traditional for the man. An important supported of the feminist trend and of the patriarchal theory in explaining violence is the Spanish author Maria Luisa Maqueda Abreu. For her, violence against women is not a biological matter, determined by the physical superiority of the man against the woman, and not even a domestic matter, but a gender based issue, result of a discrimination which "is found in the social structure of patriarchal nature" [11]. In the process of social construction, the current or older culture assigns certain roles to women and men, but preserves the masculine preponderance and the subordination of the female, which defines the relations of power between the two sexes. A similar opinion has been developed by Gafton and Turliuc [7], who consider that though each case of violence has its own features, there are certain common elements which define the phenomenon, the most important being the "stereotypical social behaviors regarding the dominant role of men and the subordination of women, gender based inequalities, briefly, the so-called patriarchal organization of the family and society, depending on the position of authority and power of men".

By drafting the Recommendation Rec (2002)5, the Committee of Ministers of the Council of Europe have started from the premise that

\footnotetext{
1 The authors explain that men show a more pronounced jealousy than women, in that men tend to exteriorize their negative feelings in a violent way, in the way women tend to internalize their feelings, developing feelings of fear and behavior avoidance. Women are especially jealous because they fear the affective involvement of the partner in the relationship with the third person, while the men are more jealous of their partner's sexual activity. These conceptual differences are the result of the fact that female jealousy develops as a strategy to avoid the woman being abandoned and deprived of resources, while the man manifests the feelings of jealousy because they see in their partner a property, a good of theirs, what would belong to them unconditionally; thus, they exercise control over the woman, in order to ensure the paternity of the descendants.
} 
gender based violence resides in the patriarchal traditions, deeply rooted in laws, in the organization and functioning of different institutions, social behaviors or perceptions and of human beings, in general [12]. Thus, it is a confirmation and a support for the theory of gender consideration, as the base for this discrimination and this type of violence.

d) The theory of stress expresses the idea that violence is the finale of a higher stress, impossible to manage differently by a disturbed and unbalanced personality.

e) According to the social etiological theory, couple aggressiveness is the result of social and individual inequity, being used by men against women to regain or keep control. In this case, violence gains different forms, from the subtlest ones to the most obvious ones, such as: social exclusion of women (i.e. disobedience to women, failure to consider their views etc.), their rejection, isolation from family or friends (girlfriends), their criticism (blaming, ridicule, injury or other forms of verbal aggression against women), threats, corruption (forced prostitution) or revictimization (blaming the woman for what is going on).

f) The theory of the attachment of the victim to the aggressor stems from the ascertainment of the fact that, in most cases, aggrieved women do not complain to the legitimate organs to unmask the abuse they are in, indefinitely enduring such behavior. Women in such situations do not even choose for a legal civil path to solve the conflict, recurring to divorce, but they "prefer" to bear such humiliating situation for "the children", from habit (negative), to not be subjected to public obloquy or because they simply cannot find another locative or economic solution for maintenance. In this case, the victim is convinced that her "welfare" and future depend on the aggressor. Asked if they were still living with the aggressor, $59 \%$ of the victims answered yes, they still do. By showing the reason why this is happening, $48 \%$ of the victims say that they still live with the aggressor because there is no other option, and $49 \%$ because it is their wish. Looking at the main reason, for which they still remain in the same housing space, $34 \%$ said they did not have the money to find another alternative, $36 \%$ said they had no place to go, $25 \%$ said they did not they want children to suffer, $15 \%$ fear what the world says, $30 \%$ say they hope their life partner will change, $33 \%$ still love him/her, 24\% say that they have become accustomed to this conflict, and that $38 \%$ think that these are problems that exist in all marriages $[13]^{2}$. The understanding of the reasons for which a woman wishes

\footnotetext{
2 The research has been concluded by the Institute for Marketing and Poles - IMAS from July-August 2003, on the following national representative sample: 1800 persons aged 18 and over, of which 1200 women and 600 men; 182 decision-makers in public institutions with attributions in this field; 190 experts from the local authorities, Police, Forensic Institute,
} 
to remain together with her aggressor is far from being elucidated. The identification of the woman with her social role of giving birth, creating, feeding (from physical to subtle) and to maintain relations (and not only) may generate in her subconscious answers difficult to evaluate. For instance, a study about therapies applicable for domestic violence, its author has presented the case of a woman, who had suffered during childhood from father's physical abuses, currently being aggressed by her husband, and who has stated that she remained in that relationship (with the husband) "in order to help bim acquire a better self-imagine" [14]. Such position reveals the fact that remaining beside the aggressor is not motivated just by weakness, dependence, incapacity of assuming the personal freedom, but by the affirmation of a feminist ideal or role, that of a healer or protector; it is more likely an assumed role as mother, than as girlfriend, which cannot match with any other feminist typology; it is a role requesting sacrifice and selfgiving, patience and a lot of uninterested love. But, SHE can assume such role willingly and for pride or self-esteem, because "women manage to make a relationship function" or for their capacity of being more emphatic and careful with other ones' needs make them feel guilty when they fail in fulfilling their curative and protective role, by feeling like betraying a feminist ideal. Beyond these beautiful aspects of the feminist side, each of those being in such delicate position and who consciously assume the role as healers or protectors, should do this under conditions in which their life, meaning and identity are not harmed, and until there where the assumed sacrifice does not become a martyrdom hard to understand.

In Romania it has been ascertained that for most cases, women frequently subjected to violent relations from the spouse or life partner, become aware of the abnormality of the situation when their children get to suffer from these violent outbursts; nevertheless, one of their important motivations to justify staying with the aggressor is that he is "a good father and the children need both parents" [5], which shows a denigration of the parental feelings (the above-mentioned statistics mentioned that $25 \%$ of the women staying with the aggressor invoke "for children's sake" reason), but also an incapacity of detaching themselves from this situation, the lack of perspective and opportunities, social prejudices, which block their perspective and holds them prisoners in a more terrible prison than a real one.

family doctors, emergency hospitals and NGOs. The PEC has developed this program with the support of the Center for Legal Resources, funded by the Open Society Institute. 
According to the theory presented, it was concluded that there are two factors that justify this abnormal behavior (the attachment of the victim to the aggressor):

- The distribution of power and the means in which is ascertained by the two partners;

- The intermittence in the commission of abuses, the moments of aggression being separated by longer or shorter quiet periods.

\section{Dismantling the arguments against.}

By analyzing from our own perspective all these theories and models and by applying them on the life, culture and social model now existing in Romania, we might say that we cannot place gender-based violence only on one theory from the ones presented. The causes of these social strain are multiple and different or each case, but there are some predominant ones regardless of the social environment in which gender-based violence occurs, of the level of education or other variables.

Although we cannot ignore the fact that some men develop violent manifestations in their couple relationships, and not only, because of the fact that at some point they suffered from a disease that affected their brain or an accident at this level, the most viable explanation for such gregarious behaviors is the anthropological conception in which most of the Romanian men grew up. For such male "examples", maintaining a relation based on power against the woman, of the control over her life and personality, sometimes by rejecting some of her behaviors [15] represent the natural of their (men) universe ${ }^{3}$. Such dominant role of man was passed for generations, as "socio-cultural or traditional model". From the content of this idea we could extract the following guidelines: not accepting that the victim has the right to a personal life or that she can make mistakes, the habit of using force for achieving a certain purpose, considering acts of domestic violence as a family secret, the absence of social protection for the victims, the fact that the aggressor seeks advantages from the humiliation and subjugation of his victim, the existence of gender-based inequalities in society, including the economic ones, preserving the idea that the man is the decision-maker etc. [16].

\footnotetext{
${ }^{3}$ the victim's resilience is given by her capacity to face suffering situations and to continue to develop. The most important trial for the victim's resilience is given by the ability to not pass her sufferance to future generations, namely her children.
} 
Together with these subjective and conceptual elements, I personally would add three conjunctural factors, in numerous cases noticed as generating forms of domestic aggressions, from threats to serious physical aggressions: excessive alcohol consumption, low incomes and low level of education.

In support of this view I shall add a few interesting statistics. A study concluded by the Pilot Center for Assistance and Protection of Domestic Violence Victims from 1996-2000 in Romania [17], revealed that 29\% of the aggressed women had a low-income level, $25 \%$ had a medium one and $20 \%$ of them had no incomes (in other words, $74 \%$ of the women victims of domestic violence had incomes below average). The same study revealed from the educational perspective that the victims of domestic violence are mainly persons with a low degree of vocational training, from medium to inferior. Thus, $29 \%$ of the victims had finished high-school, $19 \%$ just the vocational school, $16 \%$ started without completing high-school and $12 \%$ barely finished school (namely a total of $76 \%$ of them had secondary education or equivalent), unlike $7 \%$ of the victims who claimed different forms of domestic violence and who had superior training. Regarding the aggressors, only $17 \%$ of them registered high-income levels, while $57 \%$ registered an occasional income, low or very low, or its absence. Also, from the perspective of the vocational training among aggressors, it has been ascertained that domestic violence is "specific" to qualified workers, with $54 \%$, followed by unspecialized workers with $20 \%$. The smallest percentage was registered among free-lancers with $1 \%$. Among those with superior education, $8 \%$ of the men develop aggressive behaviors against their partners, while the remaining $92 \%$ are listed among those who either have no studies (1\%) or just finished high-school (21\%) or vocational training $(27 \%)$.

By comparing the statistics on the degree of training between men and women, practicing or claiming different forms of domestic violence, we can note an extraordinary similarity, for both cases the percentages climbing up to $80 \%$. According to this statistic, it results that gender-based violence is specific to couples with low level of education. Regarding the level of incomes in comparison between the two sexes we not that almost an unanimity $(89 \%)$ of the domestic violence victims have incomes below average while a fifth of the men have very high incomes, for them, gender based violence not being explained as effect of financial difficulties, as effect of the fact that money feed the feeling of power, which pushes them into controlling their life partners.

Similar conclusions were reached in the next period, from 2004 to the first semester of 2009, when the National Agency for Family Protection ascertained that among those committing domestic violence, 93\% have a 
medium level of training (namely, high-school maximum), while those with superior training develop violent manifestations to a smaller extent, the percentage being identical with that revealed by the previous study.

The study entitled National Research on domestic violence and at the workplace, in Romania, conducted by the Partnership for Equality Center in 2003 [13], included several statistics and interesting conclusions about domestic violence. According to it, it resulted that for the past 12 months (namely from 2002 to 2003), 827.000 women frequently endured domestic violence under different forms:

- 695.000 women were insulted, threatened or humiliated;

- Over 316.000 women were physically abused and a similar number suffered from abuses which led to the forced limitation of social relations;

- Over 227.000 women were deprived of their personal money or of money without their consent, by other family members; sexually.

- Over 70.000 women were abused under other forms, including

But the analyzed situation for different forms of violence, state that the Romanian society is preponderantly traditional, in which the patriarchal social models are still very present and shape the phycological structure of future men. Thus, according to the study concluded by Victoria Stoiciu [17], in Romania $58 \%$ of our co-nationals consider women must take care of the house, while $65 \%$ consider that men must earn the necessary money for the family. The issue is that most women identify themselves with this type of ideas, without even questioning if these have a real basis or not or that they could have a different life style $(64 \%$ of the women consider that they must take care of the family and $63 \%$ of them consider that men should earn the money). But things do not stop there: $39 \%$ of the Romanians consider that the family's leader is the man, $21 \%$ consider women as being the property of men and 5\% agree that "women should be beaten from time to time, even if men do not know why, she does". Such proverbial words are not single: "beating comes from Heavens" or "the man who does not beat his wife does not loves her" [13]". Starting from here, we have discovered that from 1980 to 1993, when divorces were concluded only in extremely rare situations as effect of the

\footnotetext{
4 The study National Research on domestic violence and violence at the workplace states that for $15 \%$ of the Romanians "beating comes from Heaven", for $4 \%$ "the man who does not beat his wife does not love her" and "the woman shall be beaten from time to time, because even if the husband does not know why, she does", and for $20 \%$ of them, women are the property of men.
} 
restrictive legislation during the Communist period ${ }^{5}$, violence has been invoked in $70 \%$ of the cases as the main reason [17].

\section{Conclusions.}

We strongly hope that the current study awakes the interest in deepening such complex issue as violence against women, seen as part of the domestic and gender-based violence. As it can be seen, there are numerous theories regarding the causes of this phenomenon, but the answers can only be different, related to the type of society, to cultural and historical aspects, and then to each case separately.

We consider that it must be started from the macro-social and cultural conjuncture, from the historical factor and then to evaluate each of the analyzed theories in relation to specific cases. For instance, the physiological theory cannot be totally ignored, but it cannot also be expanded for all situations; alcohol is sometimes one of the factors that inhibits control and accentuates aggression, but it cannot be extended for all cases.

In any case, the effects of this type of violence must be considered, which should be analyzed at the individual, social and economic level.

The current study is just a small part of what can be done for the understanding of this phenomenon, only a beginning, being necessary to be followed by the promotion of a legal, criminal, civil policy coherent with the types of effects ascertained for the Romanian society. The legal answer shall be correlated with the criminological and sociological studies.

\section{References}

[1]. Nicu C. Principiul egalității și deplina respectare a drepturilor fundamentale problemă de maximă importanță pentru comunitate. In: Stancu T,Odorica C.Violențaînfamilie - prevenireșicombatere. Craiova: Sitech Publ.-house; 2007: 21.

[2]. Stănoiu RM. Violența în familie. Cadrul epistemologic, Romanian Law Studies. 1999; 1-2: 153.

[3]. Beldianu I. Teorii explicative ale violenței asupra femeilor, paper drafted for the Association Pas Alternativ Brașov: 5-7.

[4]. Mastacan O. Violența în familie. Aspecte teoretice și practice. Târgoviște:

"Valahia" University Press; 2005: 23-24.

5 Though divorce was accepted, the procedure and motives determined the couple to use such situation only for extreme situations. 
[5]. Boldeanu V. Teorii despre violență. In: Stancu T, Odorica C. Violența în familie - prevenire și combatere. Craiova: Sitech Publ.-house; 2007: 10, 16, 17.

[6]. Săndulescu A, Popescu A. Profilul familiei violente. In: Stancu T, Odorica C, Violența în familie - prevenire și combatere. Craiova: Sitech Publ.-house; 2007: 28, 34-35.

[7]. Gafton L-S, Turlic MN. Gelozia - factor generator de violență domestică în cuplurile conjugale. In: Turlic N.-M., Tobolcea I., Violenţa în familie - între stigmatizare, acceptare social și intervenție terapeutică, Iași: “Alexandru Ioan Cuza" University Press; 2008: 75-78, 84-85.

[8]. Lupșa M-L, Chesnoiu Z. Forme de manifestare a violenței. In: Stancu T, Odorica C. Violența în familie - prevenire și combatere. Craiova: Sitech Publ.house; 2007: 31.

[9]. Bourdieu, P. La domination masculine. Paris: Seuil Publ.-House; 1998

[10]. Stancu, T. Definiția violenței în familie. In: Stancu T., Odorica C., Violența în familie - prevenire și combatere. Craiova: Sitech Publ.-house; 2007: 18.

[11]. Abreu MLM. La violencia de género - Entre el concepto jurídico y la realidad social. Electronic Magazine of Criminal Sciences and Criminology. 2006; 0802: 02:2.

[12]. Protecting women against violence - Analytical study on the effective implementation of Recommendation Rec (2002) 5 on the protection of women against violence in Council of Europe Member States, study concluded in 2007, available on the official website of the Council of Europe: 9. Available from: http://www.coe.int//equality/, [Accessed 6th February 2020].

[13]. ${ }^{* * *}$. National Research on domestic violence and violence at the workplace, on the official website of the Partnership for Equality Center: 64-65, 132.

Available from:

http:/ /www.cpe.ro/romana/index.php?option=com_content\&task=view\&id $=27 \&$ Itemid $=4$, [Accessed 6th February 2020].

[14]. Karner-Huțuleac A. Program de intervenție psiho- terapeutică în cazul violenței în familie. In: Turlic N.-M., Tobolcea I., Violența în familie - între stigmatizare, acceptare socială și intervenție terapeutică. Iași: “Alexandru Ioan Cuza" University Press; 2008: 250-251.

[15]. Muntean A. Toleranța culturală la forme subliminale de violență în cuplu și reziliența victimelor. In: Turlic N-M, Tobolcea I. Violența în familie - între stigmatizare, acceptare socială și intervenție terapeutică. Iași: “Alexandru Ioan Cuza" University Press; 2008: 68.

[16]. Marin M. Cauzele și consecințele violenței în familie. In: Stancu T, Odorica C., Violența în familie - prevenire și combatere. Craiova: Sitech Publ.-house; 2007: 38.

[17]. Stoiciu V.(coord). Violența domestică - manual de prevenire și combatere. Bucharest; 2003: 30, 37, 39-41, 43. 